\title{
The Impact of Air Pollution on Hospital Admissions: Evidence from Italy*
}

\author{
R. Lagravinese \\ University of Roma Tre
}

\author{
F. Moscone \\ E. Tosetti \\ Brunel University Brunel University \\ H. Lee \\ Brunel University
}

May 9, 2014

\begin{abstract}
In this paper we study the impact of air pollution on hospital admissions for chronic obstructive pulmonary disease for 103 Italian provinces, over the period from 2004 to 2009. We use information on annual mean concentrations of carbon monoxide, nitrogen dioxide, particulate matter, and ozone measured at monitoring station level to build province-level indicators of pollution. Hence, we estimate a regression model for hospital admissions, where we allow our aggregate measures of pollution to be subject to measurement error and correlated with the error term. We also adopt standard errors for estimates that are robust to serial and spatial correlation in the error term, to allow for temporal persistence and geographical concentration of unobservable risk factors.

We find that higher levels of particulate matter are associated with higher levels of hospitalisation for children, while ozone plays an important role in explaining hospital admissions of the elderly. Other factors that appear to have an effect on hospital admissions for chronic obstructive pulmonary disease are precipitation and provincial unemployment rate.
\end{abstract}

Keywords: Air pollutants; hospital admission; instrumental variables, SHAC. JEL codes: I120, I180, Q530.

\footnotetext{
*Francesco Moscone acknowledges financial support from ESRC (Ref. no. RES-061-25-0317).
} 


\section{Introduction}

Over the past decade, a substantial scientific literature has documented the size and seriousness of the impact of atmospheric pollution on the environment and the health of people. Air pollution in Europe varies substantially over time and across territory. According to the European Environment Agency many air pollutants have decreased substantially over time, resulting in improved air quality across territory. However air quality problems still persist, as air pollutant concentrations have not sufficiently declined, and a large proportion of Europe's population lives in urban areas where emission limits set by the EU National Emission Ceilings Directive are regularly exceeded. A recent report on the quality of air in Europe (Istat, 2010) shows that Italy is ranked as the third most polluted country in Europe, after Bulgaria and Greece, with more than half of the 30 most polluted cities being Italian. In particular, in the year 2008, Turin, Brescia, and Milan recorded the highest levels of overall air pollution in Europe, after the Bulgarian city, Plovdiv. Turin is also the city with the highest concentration of tropospheric ozone, although this has been reducing over time, while Naples is leading for the highest annual concentration of nitrogen dioxide, responsible for acid rains.

Atmospheric pollution threats public health with both short- and long-term effects. The former may include irritation to the eyes, nose and throat, and upper respiratory infections such as bronchitis and pneumonia. Long-term health effects can include chronic respiratory disease, lung cancer, heart disease, and even damage to the brain, nerves, liver, or kidneys. Some groups of the population may be more sensitive to pollutants than are others, such as young children and the elderly, or people with pre-existing health problems. Medical conditions arising from atmospheric pollution can require expensive treatment, leading to high health care costs, lost productivity in the workplace, and human welfare impacts, thus costing billions of dollars each year.

This paper studies the impact of air pollution on hospital admissions in Italy. Specifically, we examine the effects of a range of different pollutants, namely particular matter of size smaller than about 10 micrometers (PM10), nitrogen dioxide (NO2), carbon monoxide (CO), and ozone (O3) on hospital admissions for chronic obstructive respiratory diseases (COPD), for young children and elderly people living in 103 Italian provinces in the period from 2004 to 2009.

Respiratory illnesses are amongst the most common chronic diseases in the world, including chronic illness in younger age, and as a cause of premature mortality, leading to high socioeconomic costs. COPD is a disease state characterized by airflow limitation that is not fully reversible, accompanied by progressive lung function decline. Despite advances in therapy, 
worldwide, COPD is ranked as the sixth leading cause of death in 1990, and it is projected to be the fourth leading cause of death worldwide by 2030 (Mathers and Loncar, 2006). In Italy, COPD represents, by number, the third cause of death after circulatory diseases and cancer (Istat, 2009). Although cigarette smoking is considered the major cause of COPD, recent studies have shown that sustained exposure to exhaust fumes from both motor vehicles and industrial plants may cause development or exacerbation of chronic respiratory diseases (Gauderman, 2007; Kunzli et al. 2009; Ko and Hui, 2012).

We use information on annual mean concentration of pollutants measured at monitoring station level to build a set of province-level indicators of pollution. Relative to existing literature, one main feature of our work is that we explicitly control for possible measurement errors and endogeneity issues in our provincial measures of pollution. Indeed, pollution readings from monitoring stations may not reflect the exact amount of pollution to which people have been exposed, given that people live at different distances from stations, and they may move across territory. This issue has been identified by a recent literature in economics (e.g. Graff Zivin and Neidell, 2009; Knittel et al., 2011; Moretti and Neidell, 2011; Schlenker and Walker, 2011). In our regression model for COPD, we also allow for possible endogeneity of our pollution indicators. As pointed by Knittel et al. (2011), it is plausible to think that people living in cleaner areas could also be wealthier, have better living conditions, or have access to better health care, thus inducing a correlation between pollution and the error term. To alleviate these endogeneity problems and estimate more accurately the level of pollution within Italian provices we adopt an instrumental variables approach. As instruments for pollution we include a set of factors that are recognized to be the main drivers of pollution, including both natural sources such as climate conditions, and anthropogenic factors, i.e., generated by human activity, as well as temporal and spatial lags of pollution. We believe that adopting a instrumental variables approach where in the first-stage we use a spatio-temporal model for pollution can help researchers to study more adequately the impact of pollution on hospital admission, ultimately suggesting more reliable policy interventions.

The remainder of the paper is organized as follows. Section 2 provides a review of the literature on the effects of pollution on mortality rate and hospital admissions Section 3 introduces our econometric specification and outlines our estimation strategy. Section 4 describes the data, while Section 5 comments on the empirical findings. Section 6 concludes. 


\section{Background literature}

Over the past decade, a wide scientific literature has been documenting the size and seriousness of the impact of atmospheric pollution on the health of people. Most of these studies have focused on the effect of air pollutants on health outcomes, using data at the city, county or region level to test for the effects of prolonged exposure to air pollution, trying to identify which are the most dangerous pollutants and which segment of the population is more at risk.

Early works on the link between urban air pollution and chronic respiratory illness have been carried by Portney and Mullhay (1986, 1990), for the US. Results showed a positive relationship between ozone concentrations and sickness. Samakovlis et al. (2005) investigated the relationship between air pollution and respiratory diseases in Sweden. In particular they find that NO2 may increase risk for asthma, bronchitis and hay fever nasal problems. Jerrett et al. (2005) studied the health effects of chronic air pollution exposure within industrial cities. Their results suggested that chronic air pollution exposure significantly increases the risk of premature cardiorespiratory and cancer mortalities. Subsequent studies have also found significant associations between ozone (Bell et al., 2005) and nitrogen dioxide (Nafstad et al., 2004) on higher mortality rates. More recently, Currie et al. (2009) explored the impact of air pollutants on infant health, measured by birth weight, gestation and mortality, in New Jersey in the 1990s. The paper combined information about mother's residential location from birth certificates with information on air quality monitors. They showed negative effects of exposure to carbon monoxide on children heath, both during the pregnancy and after birth, even in areas at low levels of pollution. Agarwal et al. (2010) studied the effect of exposure to a set of toxic pollutants from manufacturing facilities on county-level infant and fetal mortality rates in the United States between 1989 and 2002. They showed a significant adverse effects of toxic air pollution concentrations on infant mortality rates.

So far, few studies have focused on the effects of air pollution on hospital admissions. Neidell (2004) studied the influence of air pollution on child hospitalisations for asthma in California. Results showed that, among the pollutants considered in the analysis, only carbon monoxide has a significant effect on hospital admissions for children, with a greater effect for children of lower socio-economic status. Dominici et al. (2006) described a short-term increase in hospital admission rates associated with PM2.5 for American Medicare enrollees, in the period between 1999 to 2002. Jayaraman and Nidhi (2008) suggested that air pollution levels in Delhi, specifically of O3, NO2 and PM10 have a significant impact on human health in terms of an increase $(24 \%, 13 \%$ and $3 \%$, respectively) in respiratory diseases related hospital visits. Namdeo et al. (2011) demonstrated association of short-term variation in pollution and health outcomes in the northern part of the UK. They founded that PM10 and O3 are positively associated with 
respiratory hospital admissions in the elderly. Rava et al. (2011) showed that proximity to wood industries is associated with a higher risk of hospitalisation for respiratory diseases and respiratory symptoms in children.

A recent related literature has emphasized that the majority of the works we have reviewed may suffer for a problem of measurement errors, thus leading to a bias in the estimates. It is likely that people have a different exposure to the amount of pollution detected from the monitoring stations. Indeed, people live at different distances from these stations, with some residing close while others far apart. Further, some people may be more mobile than others, also because of avoidance behaviour (Graff Zivin and Neidell, 2009). In other words, a mismatch is likely to exist between the amount of pollution detected and the exposure of the population to such pollution. Lleras-Muney (2010) finds that estimates are very sensitive to the technique used to impute pollution at aggregate level, and that the measurement error is not normally distributed, making the direction of the bias on estimates ambiguous. To deal with this issue, a number of works have adopted the instrumental variables (IV) approach. Chay and Greenstone (2003b) use a natural experiment to look at the relationship between pollution and infant mortality rate. The authors use the Clean Air Act of 1970 as an instrument to estimate effect of pollution on the infant mortality rate. Moretti and Neidell (2011), using zip code for the years 1993-2000, study the relationship between ozone and infant mortality rate in California (US). To alleviate possible bias resulting from the measurement error, they adopt an IV approach, using timing of port of Los Angeles traffic and distance to the port as instruments for ozone concentrations. The authors conclude that estimated effects of ozone on health are large, and that simple correlations are significantly biased by unobserved avoidance behavior and/or measurement error. Knittel et al. (2011) argue that ordinary least squares (OLS) yields inconsistent estimates of the impact of pollution on health outcomes not only because of measurement errors but also for other more broad endogeneity issues. According to the author, people living in cleaner areas could also be wealthier, have better living conditions, or have access to better health care, thus inducing a correlation between pollution and the error term. Further, changes in local economic activity may be correlated with both pollution and health. Regional growth will tend to increase pollution levels, but may also be correlated with increases in income levels and/or health care access, thus tending to bias OLS estimates. Hence, Knittel et al. (2011) adopt an IV approach to investigate the relationship between traffic, weather, pollution, and infant outcomes in California using data at zip-code level over the years 20022007. The authors use traffic congestion and weather as exogenous instruments for pollution, and find that ambient pollution levels have a large impact on weekly mortality rates. 
In this paper, we draw from the above literature and use an IV approach to deal with possible bias of OLS estimates in studying the impact of pollution on COPD hospital admissions in Italy. As instruments for pollution, we follow existing literature and take a set of variables that characterise the environment, such as climate conditions or the amount of green present in the area, as well as factors related to the presence of human activity in the area, such as traffic congestion and the concentration of manufacturing industries. In addition, we use as instruments the pollution detected in neighbouring provinces, as well as that registered in the past. The reason underlying this choice is that sources of pollution, like an industry, are likely to be persistent over time. In addition, an air pollutant originating in a particular point in space, due for example to car emissions, may propagate across a wider geographical area, given the absence of physical boundaries. Hence, augmenting the set of conventional instruments with temporal and spatial lags of pollution may contribute to better proxy pollution at aggregate level, and assess its impact on the hospital admissions.

Relative to existing literature, a further contribution of this paper is that, when studying the effect of pollution on hospital admissions, in our regression model we allow for serial dependence and spatial correlation of errors. Indeed, unobservable risk factors, such as life style variables or water contamination, which may exacerbate respiratory diseases, are likely to be temporally persistent and geographically concentrated.

\section{Empirical model}

We consider the following model for hospital admission in province $i$ at time $t, a d m_{i t}$ :

$$
a d m_{i t}=\alpha_{i}+\gamma t+\boldsymbol{\lambda}^{\prime} \mathbf{p}_{i t}+\boldsymbol{\beta}^{\prime} \mathbf{x}_{i t}+u_{i t}
$$

where the province-specific coefficients, $\alpha_{i}$, may capture time-invariant, unobserved characteristics of provinces, $t$ is a time trend, $\mathbf{p}_{i t}$ is a vector of pollutants, $\mathbf{x}_{i t}$ is a vector of control variables that may affect the dependent variable, and $u_{i t}$ is the error term. The dependent variable, $a d m_{i t}$, is hospital admissions due to COPD, divided by total population at risk. To reduce heterogeneity, in our empirical analysis we focus on two alternative groups of people; children aged between 0 and 14 years old, and people aged 65 and over. As noted by Bellander et al. (1999), and Samakovlis et al. (2005), hospitalisation may capture only part of the total effect of moderate air pollution, since most effects are less severe. Indeed, it is possible that pollutants affect the respiratory system without resulting in hospitalisations. However, we

believe that this is an important measure of public health, also reflecting the consumption of 
health care resources.

Following previous literature, amongst the regressors, $\mathbf{x}_{i t}$, we have included the average temperature and precipitation as proxies of weather conditions, since low temperatures and high precipitations may contribute to deteriorate the health status of an individual thus increasing hospital admissions. We have also controlled for socio-economic characteristics of the area, by including unemployment rate, education, and population density in our regression (see Janke et al., 2009). We have added the percentage of people regularly smoking, as this is known to be a major determinant of respiratory diseases. Finally, we have included a variable that measures the regional health deficits published annually by the Italian National Audit office (Corte dei Conti, 2010). The 311/2004 Act constrains Italian regions that are in deficit to adjust their health care expenditure in order to achieve their balanced budget. This has generated a reorganization of health care systems in the various regions in order to reduce costs, and has left little margins to adjust their supply to the demand of health care services. Hence, by including a measure of the regional health deficits we try to control for supply factors.

As noted by Janke et al. (2009), the effects of pollution may be over-estimated if temporarily elevated levels of pollution worsen the health of frail persons, for example the elderly, who would have been hospitalised anyway. While this problem maybe severe when taken as a dependent variable regarding hospitalisation of the elderly, we believe that it is milder when focusing on hospital admissions for children. As for the selected pollutants, we check the effect of PM10, NO2, CO, and $\mathrm{O} 3$ included one by one in model (1), to isolate the impact of specific pollutants, and then simultaneously, to allow for correlation between them (Salam et al., 2005; Ritz et al., 2007; Bell et al., 2007; Coneus and Spiess, 2012).

We also allow for spatial and serial correlation in the error term, using robust spatial correlation, heteroskedasticity-consistent (SHAC) standard errors for estimates, following the approach outlined in Moscone and Tosetti (2012). In the computation of SHAC standard errors we use the Parzen kernel function. Adopting SHAC standard errors is a very flexible approach that does not require specifying a spatio-temporal process for the error term (see also, Kelejian and Prucha (2007) on this).

As described in Section 4, our annual province-level indicator of pollution is likely to be subject to measurement errors, which is know to yield a bias in estimates, as well as endogenous. To deal with these issues, we adopt an IV approach. As instruments for $p_{k, i t}$ we take the temporal lag, $p_{k, i t-1}$, the spatial lag, $\bar{p}_{k, i t}=\sum_{j=1}^{N} s_{i t} p_{k, j t}$, where $s_{i j}$ are elements of a spatial weights matrix, where $s_{i j}=1 / d_{i j}$ where $d_{i j}$ is the distance in kilometers between centroids of provinces $i$ and $j$, and a set of exogeneous regressors, $\mathbf{z}_{i t}$. We include the temporal lag since the sources of pollution, such as an industry, generally continue over time, making pollution 
a temporally persisten phenomenon. We also include $\bar{p}_{k, i t}$ under the assumption that an air pollutant originating in a particular point in space, due for example to car emissions, may propagate across a wider geographical area, given the absence of physical boundaries. It is reasonable to think that such propagation will depend on the physical characteristics of the territory, for example, the altitude, the presence of mountains, or the proximity to the sea. Hence, we have decided to include province-coefficients, $\mu_{i}$, to capture such time-invariant, unobserved characteristics of provinces that explain permanent differences in pollution across provinces. The vector $\mathbf{z}_{i t}$ contains a set of variables that are likely to have an impact $p_{k, i t}$, such as the amount of green present in the area, the number of cars per inhabitant, and the number of people employed in the manufacturing sector.

To sum up, in our IV approach we first estimate a regression model for pollution, which includes province effects and spatial and temporal lags of the dependent variable amongst the regressors. We estimate such first-stage regression by Generalised Method of Moments (GMM), following the approach proposed by a very recent literature (see, among others, Kukenova and Monteiro (2009)). In particular, we have adopted the GMM by Arellano and Bond (1991), where the standard set of instruments is augmented by the spatial lags of the regressors. Once estimated the first-stage regression, predicted values for $\mathbf{p}_{i t}$ have been computed and included in (1). In our empirical study we will also report results for the first-stage regression, to show, among the included instruments, the main determinants of pollutants.

\section{Data}

Data are collected for 103 italian provinces $(N=103)$, over the period from 2004 to 2009 $(T=6)$. Data on air pollution are extracted from the AIRBASE database mantained by the European Environment Agency (EEA), while data on health outcomes and risk factors, as well as environmental data are gathered from the Italian Office of National Statistics, Istat. We refer to Table 1 for a formal definition of the variables involved in our study. We observe that the variables COPD 0-14 and COPD over 65 and over are rates concerning of the population at risk, and are expressed per 10,000 inhabitants aged between 0 and 14 years old, and 65 and over, respectively.

Data provide information on pollution concentration from a total of 592 monitoring stations spread across Italy. From Figure 1, it is evident that stations distribute more densely in the North of Italy, while they are more sparsely spread in the Centre and South regions, and islands. Starting from the information at station level, we have computed a measure of pollution at provincial level adopting a procedure similar to that advanced by Currie and Neidell (2005). 
In particular, for province $i$ in year $t$ we take the annual average daily concentration for each pollutant, registered by all monitoring stations whose distance to the centroid of the province is less than 30 kilometers (less than 15 kilometers for Milan and Rome where there are many monitoring stations within relatively small distances). By taking this approach, in certain years there are no stations around the centroid of some provinces, and therefore these provices will display missing values for our index. In line with previous studies (Neidell, 2004; Janke et al., 2009) we have considered several pollutants (PM10, NO2,CO, O3) that may cause problems of respiratory morbidity in the population.

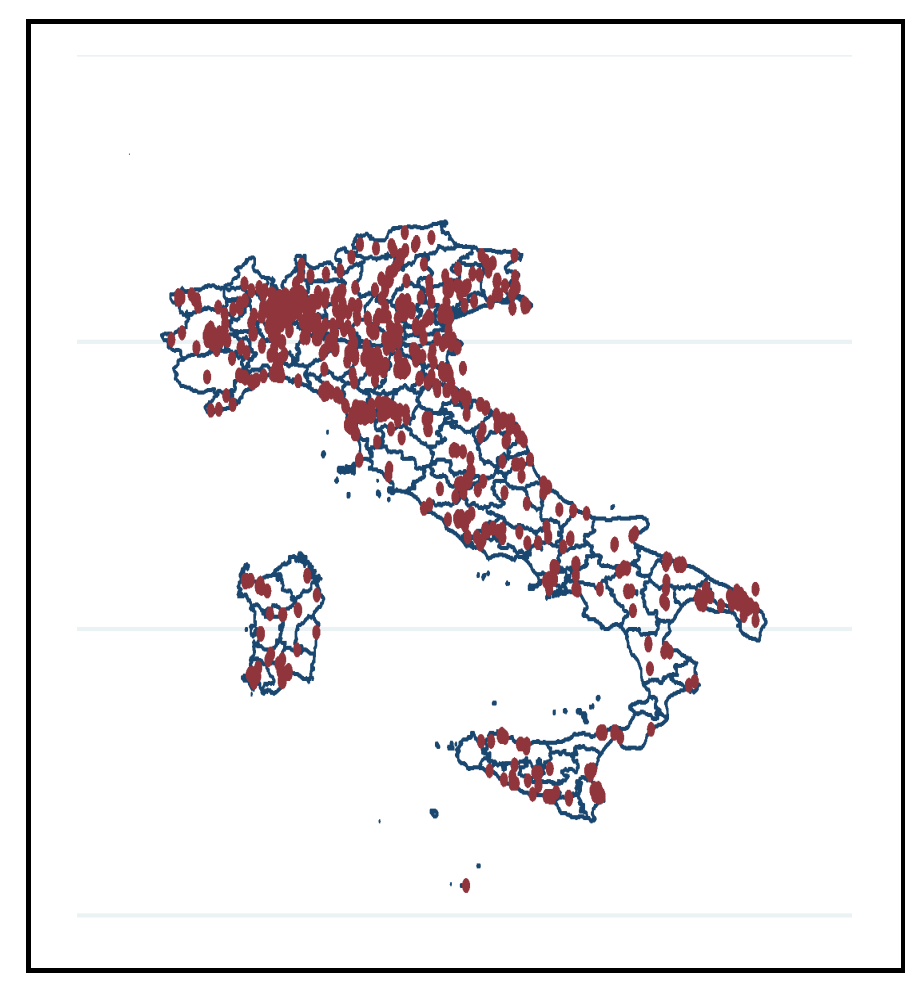

Figure 1: Location of monitoring stations 
Table 1: Definition of variables

\begin{tabular}{|c|c|c|}
\hline Variables & Unit & Description \\
\hline COPD & & Chronic obstructive pulmonary disease \\
\hline $0-14$ & n. $/ 10,000$ inhab. & n. cases in population aged $0-14$ \\
\hline Over 65 & n./10,000 inhab. & n. cases in population aged 65 and over \\
\hline PM10 & $\mu g / m^{3}$ & Annual daily average of PM10 \\
\hline $\mathrm{NO} 2$ & $\mu g / m^{3}$ & Annual daily average of $\mathrm{NO} 2$ \\
\hline $\mathrm{CO}$ & $\mu g / m^{3}$ & Annual daily average of $\mathrm{CO}$ \\
\hline O3 & $\mu g / m^{3}$ & Annual daily average of $\mathrm{O} 3$ \\
\hline Precipitation & $10 \mathrm{ml}$ & Annual average precipitation \\
\hline Temperature & ${ }^{\circ} \mathrm{C}$ & Annual average maximum temperature \\
\hline Smoking & n./100 inhab. & $\%$ of people smoking \\
\hline Unemployment & n./100 inhab. & Unemployment rate \\
\hline Green & $\mathrm{m}^{2} /$ inhab. & Green area per inhabitants \\
\hline Cars & n./1000 inhab. & Cars per inhabintants \\
\hline Manufact. & 100 employ. & People employed in the industry sector \\
\hline Education & n./100 inhab & $\%$ of people who completed high school \\
\hline Pop. dens. & n. $/ \mathrm{km}^{2}$ & Population density \\
\hline Deficit & 1,000 s Euro & Regional health deficits \\
\hline
\end{tabular}

Table 2 shows a set of descriptive statistics for the variables involved in our analysis.

From this table, it emerges that the average daily concentration of PM10 within the year is $33 \mu \mathrm{g} / \mathrm{m}^{3}$, with a maximum value of $61 \mu \mathrm{g} / \mathrm{m}^{3}$ exceeding the limit of $50 \mu \mathrm{g} / \mathrm{m}^{3}$ set by the European Community ${ }^{1}$. Nitrogen dioxide (NO2) has an average of $35.49 \mu \mathrm{g} / \mathrm{m}^{3}$, with a peak of $68.14 \mathrm{\mu g} / \mathrm{m}^{3}$, higher than the limit value of $40 \mathrm{\mu g} / \mathrm{m}^{3}$, established by the European Community. The main artificial sources of NO2 are the central heating plants, some industrial processes and the exhaust gases of motor vehicles. Carbon monoxide $(\mathrm{CO})$ can be generated by the incomplete combustion of materials containing carbon (e.g. fuels). It can also be emitted from combustion sources such as heating gas or motor vehicles. Its average concentration is $0.76 \mu \mathrm{g} / \mathrm{m}^{3}$ with a maximum of $8.64 \mu \mathrm{g} / \mathrm{m}^{3}$. The ozone (O3) in the atmosphere, is a important component of photochemical smog that even in low concentrations may cause respiratory irritation. The average daily concentration of $\mathrm{O}_{3}$ within the year is $51.63 \mu \mathrm{g} / \mathrm{m}^{3}$, with maximum points of $108.8 \mu \mathrm{g} / \mathrm{m}^{3}$.

\footnotetext{
${ }^{1}$ The limits for the protection of health are set by Ministerial Decree 60/2002 for PM10 and NO2 and Legislative Decree 183/2004 for ozone.
} 
Table 2: Descriptive statistics

\begin{tabular}{|l|c|c|c|c|c|}
\hline \multicolumn{1}{|c|}{ Variables } & Obs. & Mean & Std. Dev. & Min. & Max. \\
\hline COPD 0-14 & 618 & 29.60 & 22.10 & 12.11 & 126.38 \\
COPD 65 and over & 618 & 76.15 & 37.10 & 11.30 & 265.91 \\
PM10 & 491 & 33.26 & 8.19 & 5.48 & 61.51 \\
NO2 & 409 & 35.89 & 11.15 & 4.14 & 68.14 \\
CO & 406 & 0.76 & 0.48 & 0.01 & 8.64 \\
O3 & 398 & 51.63 & 11.44 & 16.03 & 108.80 \\
Precipitation & 618 & 78.08 & 17.368 & 40.60 & 137.87 \\
Temperature & 618 & 18.08 & 2.90 & 5.50 & 23.40 \\
Smoking & 618 & 7.24 & 1.64 & 3.90 & 11.12 \\
Unemployment & 618 & 7.33 & 4.28 & 1.85 & 21.60 \\
Green & 618 & 161.25 & 377.94 & 0.20 & $2,853.00$ \\
Cars & 618 & 632.08 & 146.33 & 411.45 & $2,104.30$ \\
Manufact. & 618 & 503.97 & 615.04 & 43.00 & $4,876.00$ \\
Education & 618 & 27.43 & 3.90 & 20.31 & 37.96 \\
Pop. dens. & 618 & $1,213.19$ & $1,374.12$ & 78.50 & $8,508.70$ \\
Deficit & 618 & 343.60 & 373.39 & 13.15 & $1,786.52$ \\
\hline
\end{tabular}

Figure 2 shows the quantile distribution of pollutants in 2009 (the last year of our analysis). The graphs show that largest concentrations of pollutants occur in areas around large cities and industrial districts, such as Turin and Naples. 


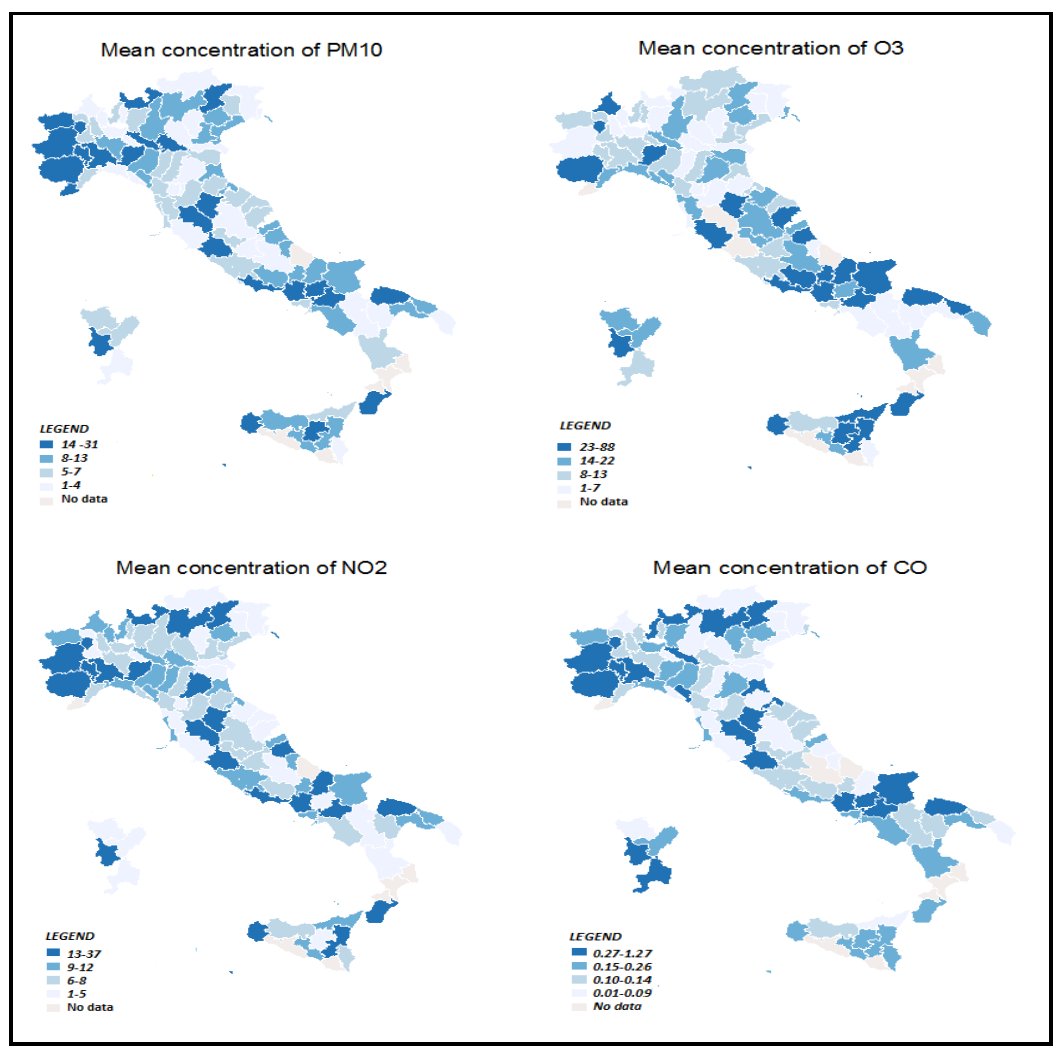

Figure 2: Quartile distribution of pollutants in 2009

In our study, hospital admissions due to COPD is used as an indicator of morbidity, differentiating between infant and elderly population. Admission rates for the elderly are considerably high, with an average of more than 76 individuals out of 10,000, reaching peaks of 266 admissions in Bari, a province in the South-East of Italy (see also Figure 3). 


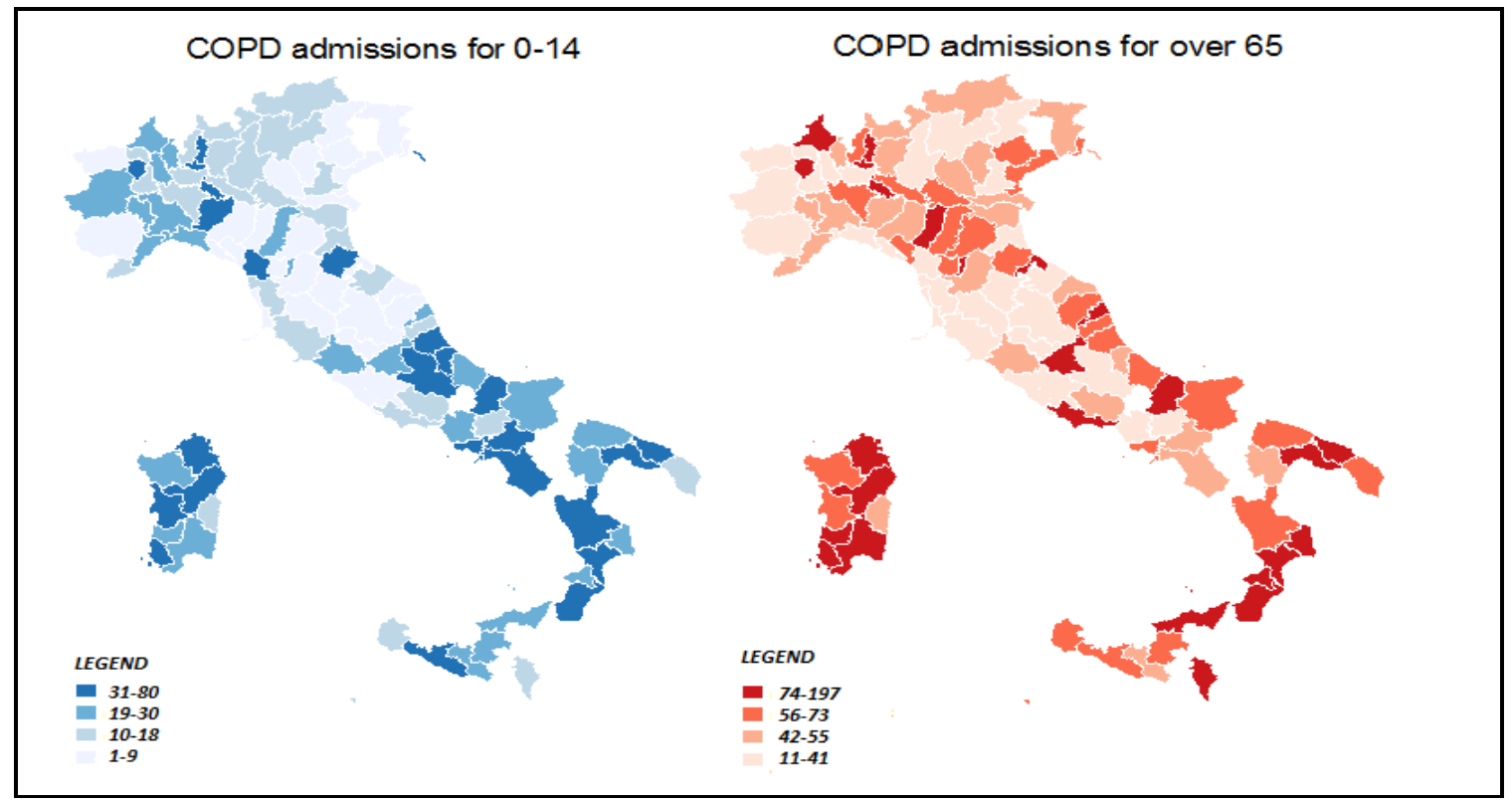

Figure 3: Quartile distribution of COPD for people aged 0-14 and people aged 65 and over, in 2009

\section{Results}

In equation (1), we have expressed the dependent variable in logs, and multiplied it by 100. Further, we have divided the pollutants PM10, O3 and NO2 by 10, so that the coefficients are estimates of the percentage change in the admission rate per $10 \mu \mathrm{g} / \mathrm{m}^{3}$ increase in PM10, O3 or NO2 or per $1 \mu \mathrm{g} / \mathrm{m}^{3}$ increase in CO. The remaining regressors have been left in their original scales (see Table 2). All computations have been performed in Matlab.

Table 3 shows the output for estimation of equation (1) when the dependent variable is COPD hospitalisation of people aged 0 to 14 years old, while Table 4 reports results for COPD hospitalisation of people aged 65 and over. Results show that PM10 has a significant impact on COPD hospitalisation for children and O3 has an influence on hospitalisation of the elderly, while it is indicated that other pollutants have no effects. In particular, a $10 \mu \mathrm{g} / \mathrm{m}^{3}$ increase in PM10 is associated with a 6.15 per cent increment in hospital admissions for children, while a $10 \mu \mathrm{g} / \mathrm{m}^{3}$ increase in $\mathrm{O} 3$ generates a 5.39 per cent rise in hospitalisation of people aged 65 and over. This implies that, on average, a $10 \mu \mathrm{g} / \mathrm{m}^{3}$ increase in PM10 would produce 2 and 4 new admissions, respectively, per 10,000 people at risk. These results should be interpreted taking into consideration that hospitalisation concerns the most severe cases, leaving out people with milder symptoms. At the same time, our estimated coefficients for pollution are higher than those computed using mortality as health outcome. For example, it is interesting that, 
similarly to our work, Janke et al. (2009) find that PM10 and O3 significantly increase allcauses mortality, once controlled for trend and region, lifestyle and weather (see, in particular, their Table 3). The authors estimate an increase in mortality of 2.80 and 0.73 per cent for PM10 and O3, respectively.

As for the other controllers, education seems to play a role in explaining variation in youth hospital admissions; a higher level of education in a province is associated with a higher probability of being admitted. More educated parents may have easier access on medical information, for example by consulting a General Practitioner (GP) or specialist, and therefore more able to identify and treat their children health conditions. The density of population has a negative impact on admissions for older people in all models. This negative sign may be associate to a constrain capacity of the hospitals. However, we have failed to find a similar pattern for the young. The variables precipitation is positive and statistically significant in all regressions for the elderly, although with a mild effect, indicating that bad weather conditions may contribute to worsen the health of older people, thus increasing hospital admissions.

The coefficient attached to the variable smoke has a positive sign when focusing on young people and including $\mathrm{CO}$ as a proxy for pollution. This result may be explained by the hazard of passive smoking. In fact, numerous studies have shown a close relation between passive smoking and diseases in young people such as respiratory illnesses, and atopy (Hawamdeh et al., 2003). In the population aged 65 and over, a higher unemployment rate is associated with a reduction in COPD admissions. A lower concentration of economic activities in areas with high unemployment may translate in lower pollution, as suggested by results shown in Table 5, and commented below. The variable trend has a negative effect on all specifications. This may in part explain the the effect of medical technologies (e.g. the adoption of pharmaceuticals such as bronchodilators, steroids, etc) over time, that has reduced hospital admissions for both vulnerable categories of the population. It is plausible that other risk factors and as well as the variable deficit, which are not statistically significant at the 5 per cent level, have little variation over time, so that part of their effect on the dependent variable is already captured by the province coefficients.

The last columns of Table 3 and 4 shows estimation results when all pollutants are included simultaneously, to allow for correlation between the pollutant levels. The coefficients on PM10 and on O3 remain significantly positive in the regressions for COPD0-14 and COPD over 65, respectively.

The Sargan tests, reported at the bottom part of the table, do not reject the null hypothesis that the instruments adopted in IV estimation are valid. Further, the Moran tests, which have been performed on the residuals of the fixed effects, are positive and statistically signif- 
icant. This confirms the presence of spatial dependence in the error term, and supports the appropriateness of the use of SHAC standard errors.

To better understand the sources of variation in pollution, we decided to report estimation results of the regression on pollution, which is the first-stage of our IV strategy. Such results may help a better understanding on the main factors underlying pollution, and thus support policy makers in tayloring more effective interventions. Results are reported in Table 5. The coefficient attached to $p_{i, t-1}$ is positive and significant for all pollutants, ranging between 0.254 for CO and 0.668 for PM10. This coefficient measures how persistent is the pollution over time, and is likely to reflect the enduring effects of the sources of pollution, both observable and unobservable. The coefficient attached to $\bar{p}_{i t}$ is positive and significant for all pollutants except for O3. This result shows that pollution generated in one point in space is likely to diffuse across a wider area, which may include cities within the same region or from different regions. The spatial effect is particularly strong for NO2 and CO, with coefficients 0.729 and 0.603, repectively. As for the remaining determinants, wider green areas tend to reduce PM10 and $\mathrm{CO}$, while, as expected, the presence of manufacturing industry increases the concentration of these pollutants in the air. Finally, the number of cars boosts NO2, through fuel combustion. It is interesting to observe that $\mathrm{O} 3$ does not seem to be affected by any of these variables. One reason for this result is that this pollutant is not emitted directly by car engines or by industrial operations, but rather formed by the reaction of sunlight on air containing hydrocarbons and nitrogen oxides.

The reported Sargan tests do not reject the null hypothesis that the instruments adopted in GMM estimation are valid. Further, while, as expected, there is evidence of serial correlation of first order, we do not observe second-order serial correlation. 
Table 3: Determinants of COPD admission for people aged 0 to 14 years old

\begin{tabular}{|c|c|c|c|c|c|c|c|c|c|c|}
\hline Variables & Coeff. & std.err. & Coeff. & std.err. & Coeff. & std.err. & Coeff. & std.err. & Coeff. & std.err. \\
\hline PM10 & $6.147^{*}$ & 2.940 & & & & & & & $6.620^{*}$ & 2.915 \\
\hline O3 & & & 0.808 & 2.344 & & & & & -1.660 & 2.064 \\
\hline $\mathrm{CO}$ & & & & & 16.748 & 16.520 & & & -4.862 & 16.617 \\
\hline $\mathrm{NO} 2$ & & & & & & & 7.279 & 4.576 & 4.759 & 7.326 \\
\hline Temperature & -7.700 & 4.566 & -8.686 & 4.495 & -8.354 & 4.511 & -7.304 & 4.557 & -6.885 & 4.536 \\
\hline Precipitation & $0.120^{*}$ & 0.030 & $0.113^{*}$ & 0.030 & $0.504^{*}$ & 0.030 & $0.203^{*}$ & 0.031 & $0.512^{*}$ & 0.032 \\
\hline Smoke & 4.434 & 2.592 & 4.033 & 2.319 & $4.652^{*}$ & 2.382 & 3.787 & 2.573 & 4.051 & 2.588 \\
\hline Unempl. rate & 0.175 & 0.188 & 0.140 & 0.180 & 0.139 & 0.174 & 0.129 & 0.184 & 0.157 & 0.183 \\
\hline Pop. density & -0.381 & 1.569 & -1.039 & 1.726 & -0.699 & 1.548 & -1.951 & 1.640 & -1.668 & 1.767 \\
\hline Education & 0.783 & 0.463 & 0.854 & 0.484 & 0.816 & 0.474 & 0.761 & 0.494 & 0.762 & 0.498 \\
\hline Deficit & 0.040 & 0.029 & 0.058 & 0.032 & 0.041 & 0.023 & 0.039 & 0.032 & 0.047 & 0.034 \\
\hline Trend & $-8.892^{*}$ & 1.296 & $-9.216^{*}$ & 1.348 & $-9.060^{*}$ & 1.296 & $-8.332^{*}$ & 1.130 & $-9.093^{*}$ & 1.276 \\
\hline Sargan test & 12.271 & {$[0.09]$} & 4.88 & {$[0.67]$} & 10.12 & {$[0.18]$} & 9.401 & {$[0.22]$} & 8.797 & {$[0.55]$} \\
\hline Moran's I & $4.12^{*}$ & {$[0.00]$} & $3.16^{*}$ & {$[0.00]$} & $3.65^{*}$ & {$[0.00]$} & $4.17^{*}$ & {$[0.00]$} & $5.65^{*}$ & {$[0.00]$} \\
\hline
\end{tabular}

Notes: $\left.{ }^{*}\right)$ : significant at the 5 per cent significance level. p-values in square brackets. 
Table 4: Determinants of COPD admission for people aged 65 years and over

\begin{tabular}{|c|c|c|c|c|c|c|c|c|c|c|}
\hline Variables & Coeff. & std.err. & Coeff. & std.err. & Coeff. & std.err. & Coeff. & std.err. & Coeff. & std.err. \\
\hline PM10 & 0.460 & 2.345 & & & & & & & -1.963 & 1.987 \\
\hline O3 & & & $5.390^{*}$ & 2.606 & & & & & $5.449^{*}$ & 2.645 \\
\hline $\mathrm{CO}$ & & & & & 2.091 & 10.835 & & & -6.358 & 10.831 \\
\hline $\mathrm{NO} 2$ & & & & & & & 9.241 & 6.807 & 4.861 & 2.505 \\
\hline Temperature & 3.705 & 2.617 & 3.978 & 2.305 & 4.055 & 2.418 & 4.335 & 2.923 & 11.233 & 6.121 \\
\hline Precipitation & $0.022^{*}$ & 0.008 & $0.025^{*}$ & 0.008 & $0.027^{*}$ & 0.006 & $0.032^{*}$ & 0.007 & $0.030^{*}$ & 0.008 \\
\hline Smoke & 0.027 & 0.898 & 0.120 & 0.921 & -0.062 & 0.942 & 0.097 & 0.934 & 0.620 & 0.894 \\
\hline Unempl. rate & $-0.190^{*}$ & 0.088 & $-0.154^{*}$ & 0.077 & $-0.141^{*}$ & 0.072 & $-0.158^{*}$ & 0.078 & $-0.167^{*}$ & 0.076 \\
\hline Pop. density & 1.275 & 1.236 & 1.180 & 1.074 & 1.274 & 1.066 & 0.908 & 0.963 & 0.998 & 0.989 \\
\hline Education & -0.103 & 0.260 & -0.269 & 0.283 & -0.222 & 0.248 & -0.176 & 0.285 & -0.257 & 0.273 \\
\hline Deficit & $-0.031^{*}$ & 0.016 & -0.004 & 0.027 & -0.004 & 0.017 & 0.003 & 0.024 & -0.001 & 0.022 \\
\hline Trend & $-10.487^{*}$ & 1.567 & $-10.989^{*}$ & 1.254 & $-11.451^{*}$ & 1.563 & $-10.773^{*}$ & 1.219 & $-10.770^{*}$ & 1.040 \\
\hline Sargan test & 8.36 & {$[0.301]$} & 10.76 & {$[0.14]$} & 13.63 & {$[0.11]$} & 16.13 & {$[0.08]$} & 14.86 & {$[0.10]$} \\
\hline Moran's I & $4.12^{*}$ & {$[0.00]$} & $3.16^{*}$ & {$[0.00]$} & $3.65^{*}$ & {$[0.00]$} & $4.17^{*}$ & {$[0.00]$} & & \\
\hline
\end{tabular}

Notes: $\left.{ }^{*}\right)$ : significant at the 5 per cent significance level. p-values in square brackets. 
Table 5: Determinants of pollution

\begin{tabular}{|l|cc|cc|cc|cc|}
\hline & \multicolumn{2}{|c|}{ PM10 } & \multicolumn{2}{c|}{ NO2 } & \multicolumn{2}{c|}{ CO } & \multicolumn{2}{c|}{ O3 } \\
\hline \multicolumn{1}{|c|}{ Variables } & Coeff. & std.err. & Coeff. & std.err. & Coeff. & std.err. & Coeff. & std.err. \\
\hline$p_{i, t-1}$ & $0.668^{*}$ & 0.109 & $0.419^{*}$ & 0.136 & $0.254^{*}$ & 0.122 & $0.564^{*}$ & 0.127 \\
$\bar{p}_{i t}$ & $0.331^{*}$ & 0.119 & $0.729^{*}$ & 0.249 & $0.603^{*}$ & 0.184 & 0.041 & 0.212 \\
Green & $-0.184^{*}$ & 0.053 & -0.084 & 0.085 & $-0.004^{*}$ & 0.002 & 0.371 & 0.464 \\
Temperature & -0.615 & 0.413 & $-1.042^{*}$ & 0.394 & -0.004 & 0.008 & -1.022 & 0.716 \\
Precipitation & -0.001 & 0.003 & 1.543 & 2.232 & -0.028 & 0.040 & 0.157 & 5.674 \\
Cars & -0.010 & 0.032 & $0.049^{*}$ & 0.019 & 0.000 & 0.000 & -0.034 & 0.071 \\
Manufact. & $0.015^{*}$ & 0.007 & 0.004 & 0.005 & $0.001^{*}$ & 0.000 & -0.010 & 0.016 \\
& & & & & & & & \\
\hline Sargan & 34.29 & {$[0.071]$} & 23.452 & {$[0.43]$} & 32.50 & {$[0.10]$} & 27.57 & {$[0.23]$} \\
\hline Ser. corr & & & & & & & & \\
\multicolumn{1}{c|}{ AR(1) } & -3.1882 & {$[0.001]$} & -2.021 & {$[0.043]$} & -2.033 & {$[0.042]$} & -2.364 & {$[0.018]$} \\
\multicolumn{1}{c|}{ AR(2) } & 1.0473 & {$[0.295]$} & 1.149 & {$[0.250]$} & -0.635 & {$[0.524]$} & 1.482 & {$[0.138]$} \\
\hline
\end{tabular}

Notes: $\left(^{*}\right)$ : significant at the 5 per cent significance level. p-values in square brackets.

\section{Concluding remarks}

In this work, we have analysed the impact of pollutants on hospital admissions for diseases related to chronic respiratory diseases in Italy. The increase of pollutants in urban areas is now at the center of academic and political debate in Italy, especially after the high-profile cases of pollution in the industrial areas of Taranto and Savona.

We have adopted an instrumental variable estimation procedure to control for possible measurement errors in our pollution variables, and other endogeneity problems, and used a spatio-temporal model for pollution in the first-stage. IV estimation shows that PM10 impacts significantly on hospitalisation of young population, while O3 increases hospitalisation of the elederly. Other factors that appear to have an important role are rainfall and unemployment. Our first-stage estimation results also show that air pollution seems to mostly determined by the presence of industrial plants, while the presence of green areas in cities lessens its concentration. A recent study by Marinaccio et al. (2011) has indicated that Taranto, which is the province with the smallest green area per inhabitants while having a large manifacturing industry and a residential area proximate to the polluting facilities, shows high and increasing trends of pleural and lung cancers. Traffic does not seem to have a significant impact on pollution and 
therefore according to our results policies of alternating plates taken in many Italian cities may not be effective. The strong spatial effects detected in pollution seem to suggest that any policy implemented to fight pollution, in order to be effective, should be taken by a set of contiguous cities, like a region or a macro-region, rather than one single city. On the other hand, our results underscore the need for further efforts on the regional and national level to reduce $\mathrm{CO}$ and PM10 levels in particular. Since these pollutants are higher in industrialised cities, environmental policies should focus on reducing pollutants in these areas in order to improve health population. The main goal of public policy should be to be able to combine industrial growth with the reduction of pollutants in order to make it sustainable in the medium to long term. 


\section{References}

[1] Agarwal, N., Banternghansa, C. Bui, L.T.M., 2010. Toxic exposure in America: estimating fetal and infant health outcomes from 14 years of TRI reporting, Journal of Health Economics 29, 557-574.

[2] Arellano M., Bond, S., 1991. Some tests of specification for panel data: Monte Carlo Evidence and an application to employment equations, Review of Economic Studies $58,277-97$.

[3] Alberini, A., Krupnick, A., 1998. Air quality and episodes of acute respiratory illness in Taiwan cities: evidence from survey data, Journal of Urban Economics 44, 68-92.

[4] Beatty, T., K.M., Shimshack, J.P., 2011. School buses, diesel emissions, and respiratory health, Journal of Health Economics 30, 987-999.

[5] Bell, M.L., Dominici, F., Samet, J.M., 2005. A meta-analysis of time-series studies of ozone and mortality with comparison to the national morbidity, mortality, and air pollution study, Epidemiology 16, 436-445.

[6] Bell, M., Ebisu, K., Belanger, K., 2007. Is risk of low birth weight affected by maternal exposure to air pollution?, Epidemiology 18, 128-228.

[7] Bellander, T., Svartengren, M., Berglind, N., Staxler, L., Jarup, L., 1999. The Stockholm study on health effects of air pollution and their economic consequences, Part II., Department of environmental health, Karolinska Hospital.

[8] Chay, K., Greenstone, M., 2003a. The impact of air pollution on infant mortality: evidence from geographic variation in pollution shocks induced by a recession, The Quarterly Journal of Economics 118, 1121-1167.

[9] Chay, K., Greenstone, M., 2003b. Air quality, infant mortality, and the Clean air act of 1970, NBER working paper 10053, National Bureau of Economic Research, Inc.

[10] Chay, K., Dobkin, C., Greenstone, M., 2003. The Clean air act of 1970 and adult mortality, The Journal of Risk and Uncertainty 27, 279-300.

[11] Coneus, K., Spiess, C.K., 2012. Pollution exposure and child health: evidence for infants and toddlers in Germany, Journal of Health Economics 31, 180-196.

[12] Corte dei Conti, 2010. Relazione sulla genstione finanziaria delle regioni. Anni 2004-2009, Roma.

[13] Currie, J. Neidell, M., 2005. Air pollution and infant health: what can we learn from California's recent experience? , The Quarterly Journal of Economics 120, 1003-1030. 
[14] Currie, J., Neidell, M., Schmieder, J.F., 2009. Air pollution and infant health: lessons from New Jersey, Journal of Health Economics 28, 688-703.

[15] Delfino, R.J., Becklake, M.R., Hanley, J.A., Sigh, B., 1994. Estimation of unmeasured particulate air pollution data for an epidemiological study of daily respiratory morbidity, Environmental Research 67, 20-38.

[16] Dominici, F., Peng, R. D., Bell, M.L., Pham, L., McDermott, A., Zeger, S.L., Samet, J.M., 2006. Fine particulate air pollution and hospital admission for cardiovascular and respiratory diseases, Journal of the American Medical Association 295, 1127-1134.

[17] Gauderman, W.J., Vora, H., McConnell, R., Berhane, K., Gilliland, F., Thomas, D., Lurmann, F., Avol, E., Kunzli, N., Jerrett, M., Peters, J., 2007. Effect of exposure to traffic on lung development from 10 to 18 years of age: a cohort study, Lancet 369, 571-577.

[18] Graff Zivin, J., Neidell, M., 2009. Days of haze: environmental information disclosure and intertemporal avoidance behavior, Journal of Environmental Economics and Management 58, 119-128.

[19] Hawamdeh, A., F. A. Kasasbeh, Ahmad, M. A., 2003. Effects of passive smoking on children's health, Eastern Mediterranean Health Journal 9, 441-447.

[20] ISTAT, 2010. Qualità dell'aria nelle città europee. Anni 2004-2009, Roma.

[21] ISTAT, 2009. Cause di morte: anni dal 1993 al 2008, Collana Annuari, Roma.

[22] Linn, W.S., Szlachcic, Y., Gong, H., Kinney, P.L., Berhane, K.T., 2000. Air pollution and daily hospital admissions in metropolitan Los Angeles, Environmental Health Perspectives 108, 427-434.

[23] Lleras-Muney, A., 2010. The needs of the Army: using compulsory relocation in the military to estimate the effect of environmental pollutants on children's health, Journal of Human Resources 45, 549-590.

[24] Janke, K., Propper, C., Henderson, J., 2009. Do current levels of air pollution kill? The impact of air pollution on population mortality in England, Health Economics 18, 1031-1055.

[25] Jayaraman, G., Nidhi, 2008. Air pollution and associated respiratory morbidity in Delhi, Health Care Management and Science 11,132-138.

[26] Jerrett, M., Buzzelli, M., Burnett, R.T., De Luca, P.F., 2005. Particulate air pollution, social confounders, and mortality in small areas of an industrial city, Social Science \& Medicine 60, 2845-2863. 
[27] Kahn, M.E., 2009. Regional growth and exposure to nearby coal fired power plant emissions, Regional Science and Urban Economics 39, 15-22.

[28] Kelejian, H.H., Prucha, I., 2007. HAC estimation in a spatial framework. Journal of Econometrics, 140, 131-154.

[29] Kelejian, H.H., Prucha, I., 2009. Specification and estimation of spatial autoregressive models with autoregressive and heteroskedastic disturbances, Journal of Econometrics $157,53-67$.

[30] Knittel, C.R., Miller, D.L., Sanders, N.J., 2011. Caution, drivers! children present: traffic, pollution, and infant health, NBER Working Paper n. 17222, National Bureau of Economic Research, Inc.

[31] Ko, F., Huy, D.S., 2012. Air pollution and chronic obstructive pulmonary disease, Respirology $17,395-401$.

[32] Kukenova, M., Monteiro, J.A., 2009. Spatial dynamic panel model and system GMM: A Monte Carlo investigation, Mimeo, University of Lausanne.

[33] Kunzli, N., Bridevaux, P.O., Liu, L.J., Garcia-Esteban, R., Schindler, C., Gerbase, M.W., Sunyer, J., Keidel, D., Rochat, T.,. 2009. Traffic-related air pollution correlates with adult-onset asthma among never-smokers, Thorax 64, 664-670.

[34] Marinaccio, A., Belli, S., et al. 2011. Residential proximity to industrial sites in the area of Taranto (Southern Italy). A case-control cancer incidence study, Ann. Ist. Super. Sanità, 47, n.2, 192-199.

[35] Mathers, C.D., Loncar, D., 2006. Projections of global mortality and burden of disease from 2002 to 2030, PLoS Med 3 (11), e442.

[36] Moscone, F., Tosetti, E., 2012. HAC estimation in spatial panels, Economics Letters 117, 60-65..

[37] Moretti, E. Neidell, M., 2011. Pollution, health, and avoidance behavior: evidence from the ports of Los Angeles, Journal of Human Resources 46, 154-175.

[38] Nafstad, P., Haheim, L.L., Wisloff, T., Gram,F., et al., 2004. Urban Air Pollution and Mortality in a Cohort of Norwegian Men. Environmental Health Perspectives 112, 610615.

[39] Nafstad, P., Haheim, L.L., Wislo, T., Gram,F., et al., 2004. Urban air pollution and mortality in a cohort of norwegian men. Environmental Health Perspectives 112, 610615. 
[40] Namdeo, A., Tiwary, A., Farrow, E., 2011. Estimation of age-related vulnerability to air pollution: Assessment of respiratory health at local scale, Environment International $37,829-837$.

[41] Neidell, M., 2004. Air pollution, health, and socio-economic status: the effect of outdoor air quality on childhood asthma, Journal of Health Economics 23, 1209-1236.

[42] Pope III, C.A., Burnett, R.T., Thun, M.J., Calle, E.E., Krewsk, D., Ito, K, Thurston, G.D., 2002. Lung cancer, cardiopulmonary mortality, and long-term exposure to fine particulate air pollution, Journal of the American Medical Association 287, 1132-1141.

[43] Portney, P., Mullahy, J., 1986. Urban air quality and acute respiratory illness, Journal of Urban Economics 20, 21-38.

[44] Portney, P., Mullahy, J., 1990. Urban air quality and chronic respiratory disease, Regional Science and Urban Economics 20, 407-418.

[45] Rava, M., Marcon, A., Girardi, P., Pironi, V., Silocchi, V., Ricci, P., De Marco, R., 2011. Proximity to wood factories and hospitalizations for respiratory diseases in children, Science of the Total Environment 410, 80-86.

[46] Ritz, B., Wilhelm, M., Hoggatt, K.J., Ghosh, J.K.C., 2007. Ambient air pollution and preterm birth in the environment and pregnancy outcomes study at the University of California, American Journal of Epidemiology 166, 1045-52.

[47] Salam, M.T., Millstein, J., Li, Y.F., Lurmann, F.W., Margolis, H.G., Gilliland, F.D., 2005. Birth outcomes and prenatal exposure to ozone, carbon monoxide, and particulate matter: results from the children's health study, Environmental Health Perspectives $113,1638-1644$.

[48] Samakovlis, E., Huhtala, A., Bellander, T., Svartengren, M., 2005. Valuing health effects of air pollution-focus on concentration-response functions, Journal of Urban Economics $58,230-249$.

[49] Schlenker, W., Walker, R., 2011. Air pollution and contemporaneous health, NBER Working Paper No. 17684, National Bureau of Economic Research, Inc.

[50] Schwartz, J., Morris, R., 1995. Air pollution and hospital admissions for cardiovascular disease in Detroit, Michigan, American Journal of Epidemiology 142, 23-35. 